\title{
B Lymphocyte Reconstitution after Human Bone Marrow Transplantation Leu-1 Antigen Defines a Distinct Population of B Lymphocytes
}

\author{
Joseph H. Antin, Kenneth A. Ault, „ Joel M. Rappeport, and Brian R. Smith \\ Department of Medicine, Division of Hematology, Brigham and Women's Hospital, Boston, Massachusetts 02115; Department \\ of Pediatrics, Division of Pediatric Oncology, Dana-Farber Cancer Institute, Boston, Massachusetts 02115; \\ and *Becton-Dickinson \& Co., Immunocytometry Systems, Inc., Mountain View, California 94043
}

\begin{abstract}
Differences in the expression of Leu-1 (CD5) define two populations of recovering $B$ cells after human marrow transplantation, Leu-1 ${ }^{+}$and Leu-1- B cells. The Leu-1 ${ }^{+}$B cells were polyclonal, of donor origin, and did not express detectable interleukin 2 receptor. Leu- $1^{+}$B cells generally appeared $2-4$ wk after marrow grafting and often preceded the recovery of Leu-1- B cells. Acute and chronic graft vs. host disease (GvHD) resulted in the recovery of significantly fewer Leu-1 ${ }^{+}$B cells, whereas Leu-1- $B$ cells were only decreased in acute GvHD. Multivariate analysis showed no significant effect of age, disease, prednisone or azathioprine, or ex vivo treatment of the marrow with anti-Leu-1 and complement on recovery of Leu-1 ${ }^{+}$and Leu-1 $1^{-} B$ cells, independent of the effects of GvHD. Leu- ${ }^{+}$B cells are a major lymphocyte population posttransplant. They may reflect a stage of differentiation of normal B cells or a separate B cell lineage.
\end{abstract}

\section{Introduction}

Bone marrow transplantation is an effective treatment for patients with leukemia, aplastic anemia, immunodeficiencies, and some disorders of metabolism. However, the weeks after the transplant are marked by abnormalities of both the cellular and humoral immune responses. These abnormalities are particularly severe in patients with graft vs. host disease (GvHD), ${ }^{1}$ and they contribute to the morbidity and mortality from opportunistic infection. Defects in T "helper" (Th), T "suppressor", and B cells have been described (1-11); however, the relative importance of defects in each compartment of the immune response is as yet unclear.

We have previously observed that in some transplanted patients, a portion of the recovering B lymphocytes expresses an unusual pattern of cell-surface antigens. These cells express Leu-

Address all correspondence to Dr. J. H. Antin, Div. of Hematology, Brigham and Women's Hospital, 75 Francis Street, Boston, MA 02115. 1987.

Received for publication 18 August 1986 and in revised form 13 March

1. Abbreviations used in this paper: Ara-c, arabinosyl cytosine; ATS, anti-thymocyte serum; Bu, busulfan; CTX, cyclophosphamide; CYA, cyclosporine; EBV, Epstein-Barr virus; FACS, fluorescence-activated cell sorter; FITC fluorescein isothiocyanate; GvHD, graft vs. host disease; IL-2R, interleukin 2 receptor; PC, procarbazine; PE, phycoerythrin; RFLP, restriction fragment length polymorphism; SCIDS, severe combined immunodeficiency syndrome; TBI, total body irradiation; Th, helper T cells; UPN, unique patient number.

J. Clin. Invest.

(c) The American Society for Clinical Investigation, Inc.

0021-9738/87/08/0325/08 \$2.00

Volume 80, August 1987, 325-332
1 (CD5) in addition to surface immunoglobulin, Leu-12 (CD19), B1 (CD20), and HLA-DR that are expressed on conventional circulating B lymphocytes (12). B cells with this phenotype are observed in human chronic lymphocytic leukemia (13) and normal human fetal spleen and lymph nodes (14-16). Leu- $1^{+}$B cells are a rare subset of $B$ cells in normal adult humans (15, $17,18)$, but some B cells can apparently express Leu-1 when activated with lectins or phorbol esters (19). A possibly analogous cell has been observed in neonatal, New Zealand black, and motheaten mice (Ly-1 B cells) (20-22). There are functional similarities and differences between human fetal spleen Leu- ${ }^{+}$ $B$ cells and murine Ly-1 B cells. In the mouse these cells are constitutive producers of IgM that tend to have autoimmune reactivity, but do not proliferate or produce specific antibodies in response to lectins or to immunization (21), and they augment the helper effects of suboptimal numbers of Th cells in a seccondary immune response (22-24); perhaps, in part due to the production of lymphokines $(22,25)$. In human fetuses, Leu- $1^{+}$ $B$ cells do not proliferate in response to lectins or constitutively produce IgM. However, they produce small amounts of IgM, but not IgG if adequate Th cells are present. Leu- $1^{+}$B cells are incapable of augmenting suboptimal numbers of $\mathrm{Th}$ cells in a primary antibody response (14). Based on the observation that Ly-1 B cells do not appear after bone marrow grafting from adult mice unless peritoneal washout cells are infused, it has been suggested that in mice the Ly-1 B cells are actually derived from a separate progenitor than conventional B lymphocytes, and that they may reflect a separate lineage of B lymphocytes (26).

This report describes studies that were designed to determine the frequency of Leu- $1^{+}$B cells after human marrow grafting, their relationship to the recovery of the humoral immune response, and the effects of GvHD on the reconstitution of these cells.

\section{Methods}

Patients. All studies were done under the guidelines of the Committee for the Protection of Human Subjects of the Brigham and Women's Hospital and the Children's Hospital Medical Center, Boston, MA. The 46 patients studied reflected a heterogeneous group of disorders transplanted at our institution over the last 3 yr. Also, several long term survivors of marrow transplantation were studied retrospectively. Clinical data are summarized in Table $I$.

Transplants were performed from fully major histocompatibility complex (MHC)-compatible donors in 38 of the 46 patients and from MHC-incompatible donors in 8 patients. The preparatory regimens varied according to the disease of the individual and are summarized in Table I. Details of the regimens have been published previously (27-29). In brief, subjects with leukemia or myelodysplasia received $500 \mathrm{mg} / \mathrm{m}^{2}$ arabinosyl cytosine (Ara-c) by continuous infusion for $7 \mathrm{~d}, 60 \mathrm{mg} / \mathrm{kg}$ cyclophosphamide (CTX) on days -3 and -2 , and 1,040-1,200 rad frac- 
Table I. Clinical Characteristics

\begin{tabular}{llllll}
\hline Diagnosis & N & Age* & Recipient preparation & $\begin{array}{l}\text { Number MHC } \\
\text { mismatched }\end{array}$ \\
\hline Leukemia & 25 & $23(1-35)$ & Ara-c/CTX/TBI & 2 & $\begin{array}{l}\text { Number T cell } \\
\text { depleted }\end{array}$ \\
Aplastic anemia & 10 & $10(3-32)$ & ATS/CTX/PC & 0 & 7 \\
SCIDS & 4 & $0.5(0.1-1.2)$ & ATS/CTX & 4 & 0 \\
Wiskott-Aldrich Syndrome & 4 & $2.5(1-8)$ & ATS/CTX/Bu & 1 & 1 \\
Other & 3 & $3(1-6)$ & ATS/CTX/Bu & - & 1 \\
& & & ATS/TBI/SI"/CYA & 1 & 1
\end{tabular}

* Median age in years (range). ${ }^{\ddagger} 11$ patients received marrow treated with anti-Leu-1 and 2 , with anti-T12. Other, Diamond-Blackfan syndrome; osteopetrosis; and myelodysplastic syndrome. "SI, splenic irradiation.

tionated total body irradiation (TBI) administered in six equal fractions over days $-3-0$. Patients with aplastic anemia received $0.2 \mathrm{ml} / \mathrm{kg}$ rabbit anti-thymocyte serum (ATS) on days $-6,-4$, and $-2 ; 12.5 \mathrm{mg} / \mathrm{kg}$ procarbazine (PC) on days $-7,-5$, and -3 ; and $50 \mathrm{mg} / \mathrm{kg}$ CTX on days -5 through -2 as described previously (27). Children with severe combined immunodeficiency syndrome (SCIDS) who received haploidentical grafts were treated similarly as patients with aplastic anemia, except they did not receive the PC. The patients with Wiskott-Aldrich and DiamondBlackfan syndromes received $3 \mathrm{mg} / \mathrm{kg}$ busulfan $(\mathrm{Bu})$ on days -9 through -6 and $50 \mathrm{mg} / \mathrm{kg}$ CTX on days -5 through -2 in addition to ATS as described above. After two unsuccessful attempts the patient with osteopetrosis was successfully transplanted with marrow from an MHCincompatible donor after preparation with ATS, followed by TBI ( 500 $\mathrm{rad}$ in a single fraction) and an additional $600 \mathrm{rad}$ to the spleen and left hemiabdomen, and $120 \mathrm{mg}$ cyclosporine (CYA) twice a day. This was the only patient who received prophylactic CYA. 13 patients received marrows that had been depleted of $T$ lymphocytes with murine monoclonal antibodies; 2 , marrows treated with anti-T12 (CD6); and 11, with anti-Leu-1 (CD5) and baby rabbit complement as previously described (29). This group included eight patients who received histoincompatible transplants and five leukemic patients who received marrow from histocompatible donors. Two patients transplanted for acute leukemia were syngeneic with their donors.

Engraftment. Engraftment was defined as $\geq 500$ granulocytes $/ \mathrm{mm}^{3}$; reticulocytes, $\geq 1 \%$; and/or platelets, $\geq 20,000 / \mathrm{mm}^{3}$ without transfusion. All patients engrafted. Mixed lymphohematopoietic chimerism was evaluated using restriction fragment length polymorphism (RFLP) analysis, as previously described (30), HLA typing, cytogenetic analysis, and red blood cell antigen typing (performed by the Center for Blood Research, Boston, MA) for 30 polymorphic red cell antigens.

GvHD. Prophylaxis for acute GvHD varied between regimens: all patients, except those who received marrow depleted of $T$ cells with the monoclonal antibody anti-T 12 and complement, received $10 \mathrm{mg} / \mathrm{m}^{2}$ per $d$ "short course" methotrexate on days $+1,+3,+6$, and +11 (31). No patients received prophylactic methotrexate after day +11 , and only one patient, prophylactic CYA. Acute and chronic GvHD were assessed according to published criteria $(32,33)$. Patients with "de novo" chronic GvHD were defined as those in whom the characteristic physical and pathologic findings of chronic GvHD occurred without evidence of prior acute GvHD. For purposes of analysis patients with acute GvHD were divided into two groups: grades 0-1 (no or mild acute GvHD) and grades 2-4 (moderate or severe acute GvHD). Acute GvHD was treated initially with high dose methylprednisolone (3-5 mg/kg per $\mathrm{d}$ for 5-10 d) in all cases. Some patients with refractory GvHD received ATS, and one patient was treated with CYA for established GvHD that was resistant to prednisone and ATS. Patients with chronic GvHD were treated with 1-2 $\mathrm{mg} / \mathrm{kg}$ prednisone every other day and $1 \mathrm{mg} / \mathrm{kg}$ per $\mathrm{d}$ azathioprine. The prednisone and azathioprine were tapered over 6-12 mo. Treatment was continued for 6 mo or longer until resolution of the signs of chronic GvHD. No patients received prophylactic immunoglobulin infusions.

Immunofluorescence and flow cytometric analysis. We examined blood lymphocytes in 26 normal subjects and in 46 transplant patients at various times after recovery from marrow transplant by multiparameter flow cytometry as described previously (12). In brief, mononuclear cells were prepared by Ficoll-Paque (Pharmacia Fine Chemicals, Div. of Pharmacia Inc., Piscataway, NJ) density-gradient centrifugation. Monocytes were depleted from blood samples by either overnight plastic adherence of mononuclear cells or incubation of the blood with carbonyl iron (Technicon Instruments Corp., Tarrytown, NY), followed by FicollPaque centrifugation and overnight plastic adherence. $5 \mu l$ of phycoerythrin (PE)-conjugated anti-Leu-1 (Becton-Dickinson \& Co., Mountain View, CA) and $5 \mu$ l of fluorescein isothiocyanate (FITC)-conjugated monoclonal anti-B1 (Coulter Electronics Inc., Hialeah, FL) or antiLeu-12 (Becton-Dickinson \& Co.) antibodies were added to each aliquot of $4 \times 10^{5}-5 \times 10^{5}$ cells at $4^{\circ} \mathrm{C}$ and incubated for $15-30 \mathrm{~min}$ in the dark. The cells were then washed three times with ice-cold phosphatebuffered saline. Background staining was determined with PE- or FITCconjugated "irrelevant" control mouse monoclonal antibodies of the same Ig isotype (Becton-Dickinson \& Co.). Correlated dual-parameter data were obtained on a fluorescence-activated cell sorter (FACS) (model 440; Becton-Dickinson \& Co.) or FACS Analyzer (Becton-Dickinson \& Co.) and analyzed on a minicomputer (PDP-11/23, Digital Equipment Corp., Maynard, MA) or a microcomputer (Series 200, Hewlett-Packard Co., Palo Alto, CA). Data were obtained using log amplifiers and displayed as contour plots on a $64 \times 64$ grid. Quadrants were established by using the upper level of positivity of conjugated irrelevant mouse antibodies. Erythrocytes were excluded from analysis by labeling leukocytes with an FITC-conjugated antibody to the pan-leukocyte antigen HLE1 (Becton-Dickinson \& Co.), and percentages of cells measured in the experiments were adjusted accordingly (12). Data were collected on $0.5 \times 10^{4}-$ $5 \times 10^{4}$ cells for each pair of fluorescent labels. Wide-volume gates were used to be sure all lymphocytes were included, and the number of monocytes was determined by labeling the cells with the monocyte-specific monoclonal antibody, PE anti-Leu-M3 (Becton-Dickinson \& Co.). Absolute lymphocyte counts were established by multiplying the white blood cell count, as determined on a counter (Coulter Electronics Inc.), by the percent lymphocytes observed on Wright-Giemsa-stained blood smears. Cells were analyzed for the presence of the interleukin 2 receptor (IL2R) by labeling with FITC- or PE-conjugated anti-IL-2R (Becton-Dickinson \& Co.) and analyzing the data as described above.

B cells from a patient with SCIDS (unique patient number [UPN] $128 \mathrm{H}$ ) who underwent a haploidentical transplant from his mother and B cells from a patient transplanted with marrow from his histocompatible sister for aplastic anemia (UPN 087) were incubated with Epstein-Barr virus (EBV), and EBV-transformed B cell lines were established. These cells were maintained in culture for $>2$ mo and labeled as above to look for Leu-1 expression.

Other. Quantitative serum immunoglobulins were measured by the Center for Blood Research. Levels were done monthly in most cases. Statistical analysis was performed on a statistical software (Systat, Evanston, IL). Matched-pair $t$ tests, stepwise-multivariate linear regression, multiple-logistic regression, and Wilcoxon and Kruskal-Wallis tests were 
used where noted. Life table analysis and log rank testing was performed as described by Peto et al. (34).

\section{Results}

Immunofluorescence. As demonstrated in Fig. 1, dual-fluorescence analysis demonstrated a population of $\mathrm{B}^{+}$cells in which the surface expression of Leu-1 was lower than the expression observed on mature $T$ cells. In previous experiments (12) similar posttransplant cells were shown to be polyclonal B cells by simultaneously labeling them with the B cell-specific antibodies anti-Leu-12, anti-B1, anti-IgD, anti-IgM, and anti-IgG and by examination of heavy- and light-chain Ig gene rearrangements. None of the patients had B cells that were labeled with anti-IL$2 R$. To establish the normal range of Leu- $1^{+} B$ cells in peripheral blood of adults, we examined 26 normal blood donors for the presence of Leu- $1^{+}$and Leu-1 ${ }^{-}$B cells by co-labeling cells with anti-Leu-1 and anti-Leu-12. We found that Leu- $1^{-}$and Leu$12^{+}$cells accounted for $7 \pm 4 \%$ (mean \pm SD) of circulating lymphocytes and for an absolute count of $168 \pm 96 \mathrm{cells} / \mathrm{mm}^{3}$ in normal subjects. Leu- $1^{+}$and Leu- $12^{+} B$ cells were less frequent, which accounted for $1 \pm 3 \%$ of circulating lymphocytes and for an absolute count of $24 \pm 72$ cells $/ \mathrm{mm}^{3}$. The B cells from the individual with SCIDS (UPN 128H) and the patient with aplastic anemia (UPN 087) from which EBV-transformed cell lines were

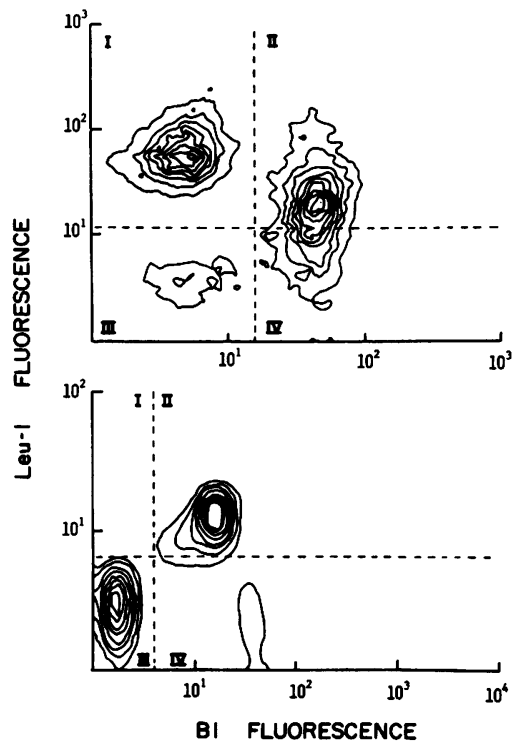

Figure 1. Dual parameter fluorescence histograms of lymphocytes studied after bone marrow transplantation. The data were obtained by selecting lymphocytes based on forwardangle light scatter and simultaneously measuring red (PE) and green (FITC) fluorescence. In both cases the location of quadrant markers was determined on control samples incubated with conjugated irrelevant mouse immunoglobulin. Top, PE antiLeu-1 and FITC anti-B1 labeling of 5,000 lymphocytes from a patient

(UPN 206S) who underwent a syngeneic transplant for acute leukemia 6 wk before. There were 35\% T cells (quadrant $I$ ), 35\% Leu- $1^{+}$B cells (quadrant $I I$ ), and $18.5 \%$ Leu-1 ${ }^{-}$B cells (quadrant $I V$ ). In this case the expression of B1 is equivalent on the Leu- $1^{+}$and Leu-1- B cells, and Leu- 1 expression is manifested as a continuous distribution in the population of B cells. Bottom, PE anti-B1 and FITC anti-Leu-1 labeling of 50,000 lymphocytes from a patient (UPN 176) who underwent an allogeneic transplant with marrow that had been depleted of $T$ cells with anti-Leu-1 for chronic myelogenous leukemia 6 wk before. In contrast to the patient in the top, Leu-1 defined two discrete populations of B cells, and the Leu- ${ }^{-}$population had greater cell-surface expression of the B1 antigen. There were $8.7 \% \mathrm{~T}$ cells (quadrant $I$, these cells are not demonstrated with the $10 \%$ contour line used in this figure), 37.1\% Leu-1 $1^{+}$B cells (quadrant $I I$ ), and $15.9 \%$ Leu-1- B cells (quadrant $I V$ ). The axes are labeled in arbitrary units of fluorescence on a logarithmic scale. established were 50 and $80 \%$ Leu- $1^{+}$, respectively. Both cell lines were $>95 \% \mathrm{Bl}^{+}$, Leu- $12^{+}$, and surface $\mathrm{Ig}^{+}$and $<2 \% \mathrm{Leu}-4^{+}$. The B cell line derived from UPN $128 \mathrm{H}$ was of host origin and that from UPN 087 was of donor origin. In both cases the origin was established by RFLP analysis (30). Neither of the B cell lines expressed detectable Leu-1.

Recovery of Leu- $1^{+}$and Leu-1- $B$ cells as a function of time after transplant. B lymphocytes were generally not observed until $\sim 3$ wk after transplant in patients with grades 0-1 GvHD (Fig. 2) and often recovered concomitantly with the recovery of myeloid marrow elements. In 6 of the 20 patients who were followed serially, the appearance of Leu- $1^{+}$B cells preceded that of conventional, Leu-1 ${ }^{-} B$ cells by 1-2 wk. In the remaining 14 patients the two types of B cells appeared simultaneously. After the 1st mo both types of $B$ cells tended to be present in equal numbers, and as Fig. 3 demonstrates both Leu- ${ }^{+}$and Leu-1- $B$ cells persisted at high levels for at least 1 yr after the transplant (matchedpair $t$ test and Wilcoxon matched-pair ranked sums, $P \gg 0.05$ ). Note that in individual patients the numbers of Leu- ${ }^{+}$and Leu$1^{-}$B cells often varied without apparent relation to clinical events (Fig. 2). Both types of B lymphocytes were demonstrable as long as $5 \mathrm{yr}$ after marrow grafting; however, there seemed to be a

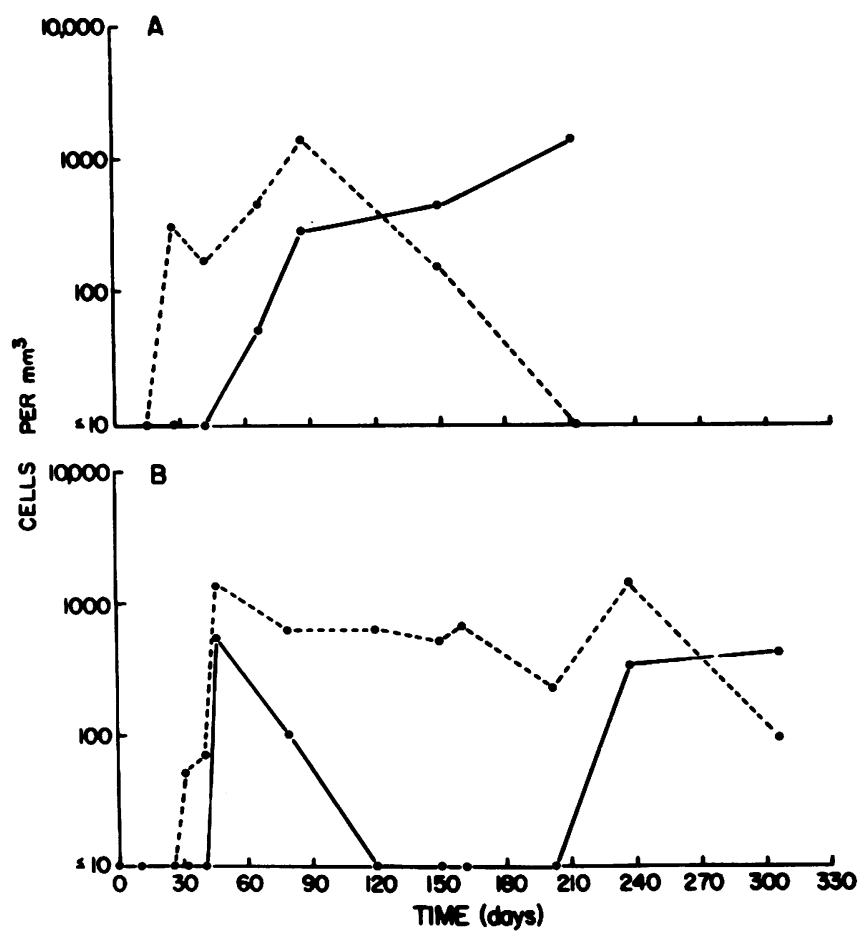

Figure 2. Representative pattern of recovery of Leu-1 ${ }^{+}$and Leu-1- $B$ cells as a function of time after bone marrow transplantation in two patients with no evidence of GvHD. The solid line represents Leu-1$B$ cells and the dashed line, Leu- $1^{+}$B cells. The patient in $A$ (UPN 155S) had a syngeneic transplant for acute lymphoblastic leukemia. The patient in $B$ (UPN 151) had an allogeneic transplant for acute myelogenous leukemia after $\mathrm{T}$ cell depletion of the donor marrow with anti-Leu-1. In both cases there was a rapid recovery of Leu- $1^{+} B$ cells that preceded the recovery of Leu- $1^{-}$B cells. The number of B cells was at times quite high, reflecting as many as 30-40\% of total circulating lymphoid cells. There were 3 mo (between 120 and $200 \mathrm{~d}$ ) when we were unable to detect Leu-1- $B$ cells in UPN $151(B)$; there was no clinical GvHD during that time. The range for Leu- $1^{-}$and Leu- $1^{+}$B cells in normal individuals is $168 \pm 96$ and $24 \pm 72$ cells $/ \mathrm{mm}^{3}$, respectively. 


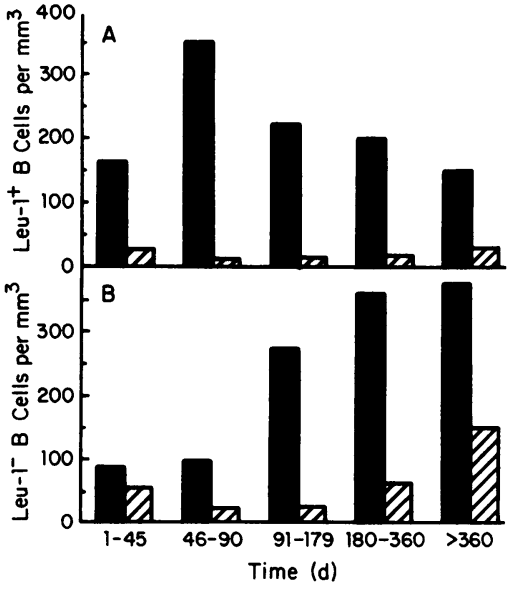

作 cells for as long as $5 \mathrm{yr}$ after transplantation. If GvHD was present, there was minimal recovery of Leu-1 ${ }^{+}$B cells. $B$, Leu-1- $B$ cells took longer to recover initially and tended to rise as the numbers of Leu- $1^{+}$ cells decreased. GvHD resulted in reduced numbers of Leu-1- $B$ cells, but the numbers of these cells increased in conjunction with the resolution of GvHD. They appeared to be less sensitive to the effects of GvHD than Leu- $1^{+}$B cells. The range for Leu- $1^{-}$and Leu- $1^{+}$B cells in normal individuals is $168 \pm 96$ and $24 \pm 72$ cells $/ \mathrm{mm}^{3}$, respectively. Statistical analysis of this data is presented in Table II.

tendency for the relative numbers of Leu- $1^{+}$cells to decline $\sim 1$ yr after the transplant, but the data did not reach statistical significance (Table II, Fig. 3). Even longer than 1 yr after transplant, some patients continued to have absolute Leu- $1^{+}$B cells counts that were substantially higher than normal subjects (Table II).

Effects of $G v H D$ on recovery of $B$ lymphocytes. GvHD had a profound effect on the recovery of both classes of B cells (Fig. 3). In the absence of GvHD there was prompt recovery of Leu$1^{+}$B cells to levels more than two standard deviations above normal 46-90 d after transplant. There was then a gradual reduction in the numbers of Leu- $1^{+}$B cells. In contrast, Leu- $1^{-}$ $B$ cells recovered to near normal levels in the 1 st 3 mo after transplant, but subsequently increased concomitantly with the reduction in Leu- $1^{+}$B cells. Either acute or chronic GvHD resulted in dramatic reductions in the numbers of both classes of B cells.

To assess the patients for independent effects of acute and chronic GvHD, those with grades 2-4 acute GvHD were examined for B cell recovery in the 1 st 3 mo after transplant since most acute GvHD occurs in that interval. In contrast to patients with grades $0-1$ acute GvHD, patients with grades 2-4 acute GvHD had significantly fewer $(P<0.025)$ of both types of B cells (Table II). Only 2 out of $11(18 \%)$ patients with acute GvHD recovered any detectable phenotypic $B$ lymphocyte during this interval, one in the 2 nd mo and the other in the 3rd mo after transplant. The patient whose Leu- $1^{+} \mathrm{B}$ cells recovered in the 2nd mo after transplant had grade 3 acute GvHD; she did not develop chronic GvHD and is alive and well. The patient whose Leu- $1^{+}$B cells recovered in the 3 rd mo posttransplant developed chronic GvHD and died of cytomegalovirus infection. There were too few patients who developed acute but not chronic GvHD so as to be able to assess the recovery of Leu- $1^{+}$B cells in that setting.

B cell recovery was assessed after $90 \mathrm{~d}$ in individuals who developed chronic GvHD. Chronic GvHD prevented the reconstitution of Leu- $1^{+}$B cells disproportionately to the recovery of Leu-1 ${ }^{-}$B cells when compared with patients without chronic GvHD (Table II). Thus, in patients with chronic GvHD there were significantly fewer Leu- $1^{+} \mathrm{B}$ lymphocytes present between $90 \mathrm{~d}$ and $1 \mathrm{yr}$ than in patients with no GvHD, however, the numbers of Leu- $1^{-}$B cells were similar in both groups. 12 mo after transplant was chosen as a time when chronic GvHD was resolving in many patients. There was no significant difference as measured by the Kruskal-Wallis test in the numbers of either

Table II. Comparison of Recovery of Leu-1 ${ }^{+}$and Leu-1- B Cells by GvHD Status and Time after Transplant

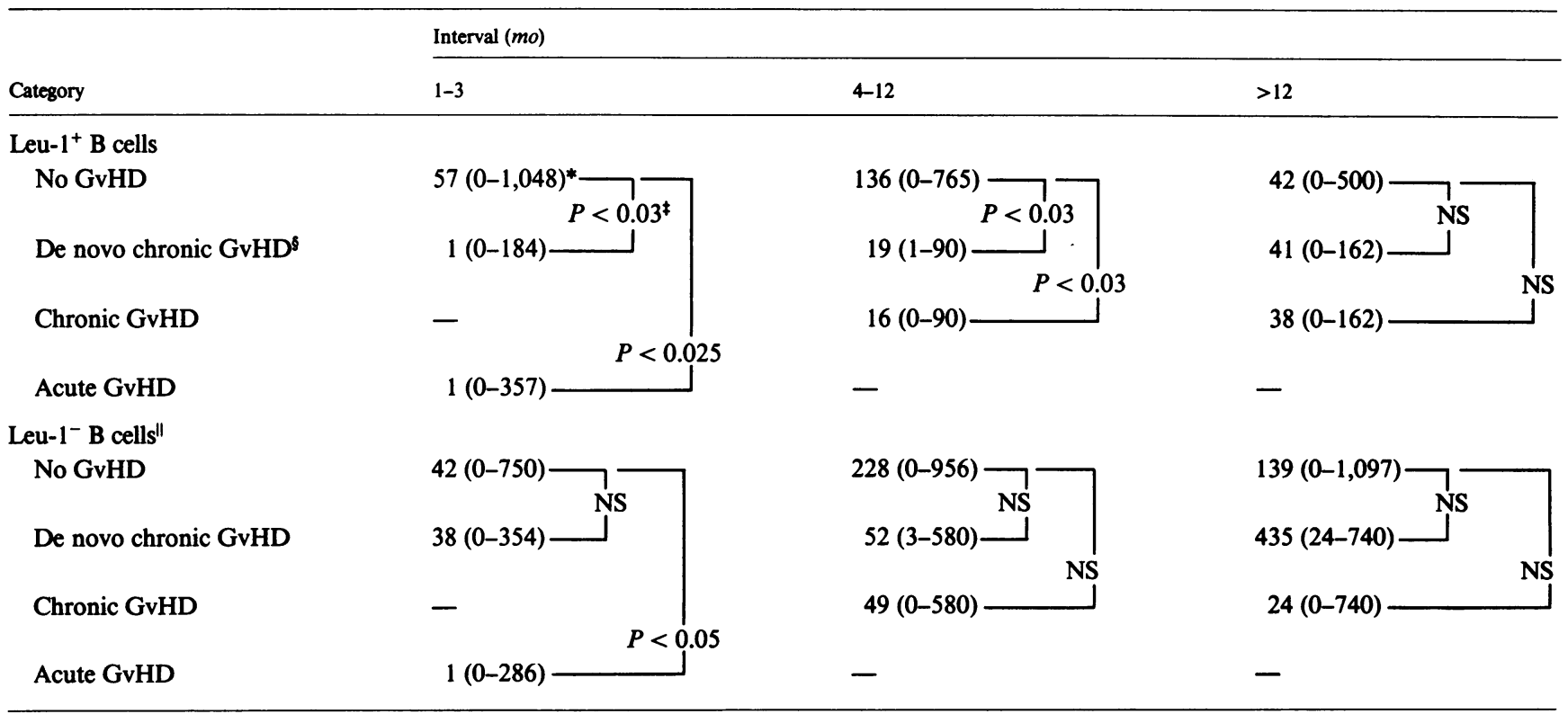

* Values are median (range) absolute counts. ${ }^{\ddagger}$ Differences between categories within the same interval were determined with the Kruskal-Wallis test. "De novo chronic GvHD, chronic GvHD without prior actute GvHD. "There were no significant differences between Leu-1 ${ }^{+}$and Leu-1cells within intervals, as determined with the Wilcoxon matched-pair ranked sums or matched-pair $t$ tests. 
subset of B cells in patients who survived 1 yr or longer regardless of their GvHD status (Table II).

Interestingly, there was a suggestion that the effects of acute and chronic GvHD could not be dissociated. When the patients who developed de novo chronic GvHD (i.e., without prior clinical acute GvHD) were examined separately, the reconstitution of both Leu- $1^{+}$and Leu- $1^{-}$B cells was no different than that for subjects with acute GvHD. This paucity of Leu- $1^{+}$B cells persisted until resolution of the chronic GvHD. The reduction in Leu- $1^{+}$B cells did not extend to Leu- $1^{-}$B cells $(P>0.05)$ (Table II).

We examined the probability of recovery of Leu- $1^{+}$B cells in a life table analysis (Fig. 4). An event was considered to be the first demonstration of $\geq 5 \%$ Leu- $1^{+} \mathrm{B}$ cells in the blood. Patients were censored at the time of death if Leu- $1^{+}$B cells had not yet appeared. This analysis showed that patients without GvHD had a more rapid recovery of Leu- $1^{+}$B cells, and that surviving patients with GvHD did recover Leu- $1^{+}$B cells, but somewhat later. Log rank analysis demonstrated that the patients with either acute or chronic GvHD were significantly $(P<0.05)$ less likely to have recovery of Leu- $1^{+} B$ cells at 1 yr after transplant than patients with no GvHD. This difference disappears in the 2 nd yr after transplant.

Relationship of the recovery of Leu- $\mathrm{I}^{+} \mathrm{B}$ cells to other factors. There was no difference in prevalence of Leu- $1^{+}$B cells when analyzed by disease, preparative regimen, or age of patient or donor. Since 11 of our patients received marrow that had been depleted of $\mathrm{T}$ lymphocytes with the monoclonal antibody antiLeu-1, which recognizes the CD5 surface antigen, we asked whether these patients had any difference in the pattern of Leu$1^{+}$B cell recovery. There were no differences in recovery of either type of B cell in this subset of patients (multivariate analysis of variance, $P \gg 0.5$ ). The effects of azathioprine and prednisone could not be differentiated from those of GvHD in this study by multivariate analysis. All of the patients reported had recovery of blood leukocytes to levels consistent with engraftment. RFLP analysis and cytogenetics demonstrated that most patients were completely engrafted with donor cells. The exceptions were one patient who had a clinical relapse of chronic myelogenous leukemia and the four patients with SCIDS. The B cells of the patient with chronic myelogenous leukemia were not further characterized, but in the patients with SCIDS all of the lymphoid cells were of donor origin, whereas the myeloid cells were of recipient origin. Data from the patient with relapsed chronic

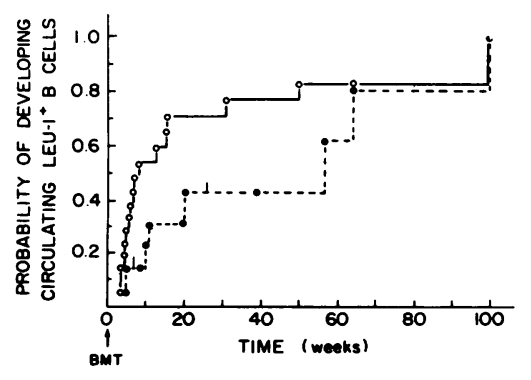

Figure 4. Life table analysis of the recovery of Leu- $1^{+}$B cells after bone marrow grafting. The solid line denotes patients with no acute or chronic GvHD. The arrow at time zero indicates the bone marrow transplant (BMT). Patients who developed either acute or chronic GvHD at any time during their posttransplant course are represented by the dashed line. Censored patients are indicated with a tic mark. At 1 yr the likelihood of having circulating Leu$1^{+}$B cells was significantly greater in the absence of GvHD ( $\chi^{2}$ $=3.828, P<0.05$ by the $\log$ rank test), whereas at $2 \mathrm{yr}$ the difference was no longer observed $\left(\chi^{2}=1.967, P>0.05\right)$. myelogenous leukemia were censored at the time of relapse; however, she demonstrated Leu- $1^{+}$B cells before relapse.

Relationship of B cell subsets to serum immunoglobulin levels. We examined the relationship between serum immunoglobulin levels, after 6 wk posttransplant, and numbers of circulating B lymphocytes. The serum IgG weakly correlated with the total number of B cells (logistic regression: $r=0.357, P<0.01$ ) as well as with each subset of $B$ cells (multivariate logistic regression: Leu- $1^{+}$B cells, $r^{2}=0.138, P<0.01$; and Leu- $1^{-}$B cells, $r^{2}$ $=0.129, P<0.01)$. There was a similar weak correlation between total B cells and serum IgM (logistic regression: $r=0.379, P$ $<0.01$ ), but analysis by Leu- 1 status failed to show a significant relationship. The same relationship was apparent when the patients were analyzed by chronic GvHD status. There was no correlation between either total B cells or either type of B cell with serum IgA levels.

\section{Discussion}

Several investigators have studied the recovery of the humoral immune response after bone marrow transplantation, and defects in the regulatory capabilities of $\mathrm{T}$ lymphocytes as well as deficiencies in the numbers and responses of $B$ lymphocytes have been described (1-11). There is general agreement that immunologic responsiveness in vivo and in vitro regenerates slowly in the months to years after marrow grafting and that the rate of recovery and loss of qualitative defects in both cellular and humoral responses are dependent to a large extent on the presence of GvHD. The generalized defects in immunity are largely responsible for the morbidity and mortality from late infection that is observed after marrow transplantation.

We have been particularly interested in an unusual population of B cells, that are prominent in many transplanted patients without GvHD. These B cells co-express the cell-surface antigen Leu-1 (CD5) with more usual B cell-surface proteins HLA-DR, Leu-12, B1, IgM and IgD (12). Although Leu-1 is primarily associated with $\mathrm{T}$ lymphocytes, B lymphocytes that express Leu-1 have been described in man, in human fetal lymphoid organs, and in some malignant B cells (13-17). However, in contrast to malignant Leu- ${ }^{+} \mathrm{B}$ cells, Leu- $1^{+} \mathrm{B}$ cells that recover after marrow grafting are not monoclonal (12) and do not express IL-2R.

A murine antigen, Ly-1, is similar to human Leu-1, and a possibly analogous B cell population (Ly-1 B cells) has been found in neonatal, New Zealand black, and motheaten mice, where they produce IgM and/or IgG3 that tends to have autoimmune reactivity (20-22). Furthermore, Ly-1 B cells do not respond to immunization with production of specific antibodies, and they may be able to provide allotypic and idiotypic helper cell function to suboptimal numbers of Th cells in a secondary immune response. It has been suggested that the tendency to produce anti-idiotype antibody and lymphokines is related to their possible function in the control of Ig synthesis (22-25). Numbers of Ly-1 B cells diminish with the aging of mice (21). Similar to the mouse, Leu- $1^{+} B$ cells are prominent in the human fetus, but they become less numerous in adults. Leu- $1^{+} \mathrm{B}$ cells contrast with Ly-1 B cells in that they only produce small amounts of IgM.

In our transplant patients there were no differences in B cell reconstitution that were dependent on the diagnoses or the pretransplant preparation between any of the groups we studied. The patients with aplastic anemia were no different from the 
patients with leukemia and other patients who received preparative therapy, which is generally considered to be toxic to stem cells. We were particularly interested in patients who did not receive "ablative" therapy since Hayakawa and co-workers (26) demonstrated chimeric Ly-1 B cells in mice that had been irradiated with $500 \mathrm{rad}$, a radiation dose that may result in mixed hematopoietic as well as lymphoid chimerism (35). Even though the transplant conditioning regimen we used for patients with aplastic anemia would not necessarily be expected to result in irreversible B cell injury, we have shown using RFLP analysis that the Leu- $1^{+}$B cells in our patients were of donor origin and not monoclonal populations (12).

There were too few children with severe combined immunodeficiency to say whether the known heterogeneity of B lymphocyte numbers in this syndrome was reflected in different numbers of Leu- $1^{+}$B cells after transplantation. It is conceivable that we would have observed different patterns of B cell recovery in children in whom there were B cells before transplant in comparison with children with no preexistent B cells. We suspect that children with SCIDS who have no preexistent B cells will demonstrate the pattern of $B$ cell recovery seen in other disorders.

Although some of the patients received marrow that had been purged of Leu-1-bearing cells with anti-Leu-1 and complement, we saw no difference in the rate of recovery or numbers of Leu- $1^{+}$B cells in these patients. Since Leu- 1 is expressed weakly on B cells, it is possible that a Leu- $1^{+}$B lymphocyte precursor escaped lysis or that the Leu- $1^{+} \mathrm{B}$ cell precursor does not express Leu-1. Hayakawa and colleagues have suggested that in the mouse, $\mathrm{Ly}-1^{+} \mathrm{B}$ cells and conventional $\mathrm{Ly}-1^{-} \mathrm{B}$ cells are derived from separate precursors. This contention was supported by the observation that reconstitution of blood $\mathrm{Ly}-1^{+} \mathrm{B}$ cells did not occur if the mice were transplanted with adult murine bone marrow alone. If peritoneal washout cells were added or marrow from neonatal mice was used, $\mathrm{Ly}-\mathrm{I}^{+} \mathrm{B}$ cells are regenerated normally (26). Although our data are not conclusive, they suggest that in humans, Leu- $1^{+} B$ cells are regenerated regardless of the age of the donor, even from marrow treated with lytic anti-Leu1 antibody and complement under conditions sufficient to delay T lymphocyte recovery (36). Furthermore, two syngeneic patients had numbers of Leu- ${ }^{+}$B cells that were indistinguishable from the allogeneic patients, suggesting that minor, non-HLA histocompatibility differences do not contribute to the presence of Leu- $1^{+}$B cells in humans. Thus, no evidence exists for a separate precursor in humans.

Both acute and chronic GvHD had profound effects on the reconstitution of B lymphocytes, however, Leu- $1^{+}$B cells were particularly sensitive to the effects of GvHD. In patients who developed acute GvHD (grades 2-4) there was rarely any recovery of Leu- $1^{+}$or Leu- $1^{-}$B cells in the 1 st 3 mo after transplantation. Patients with chronic GvHD generally recovered Leu$1^{-}$B cells during the 4-12 mo after marrow grafting, however, the Leu- $1^{+}$B cells did not achieve levels similar to patients without GvHD until 1 yr later. The recovery correlated with the time course of resolution of chronic GvHD. When patients who developed de novo chronic GvHD were analyzed separately, it was apparent that the temporal course of B cell recovery did not depend on the presence of clinical GvHD. These patients had abnormal recoveries of both Leu- $1^{+}$and Leu- $1^{-}$B cells during the 1 st 3 mo after marrow grafting, indicating that although clinical acute GvHD could not be demonstrated, this characteristic abnormality of B cell recovery was present. The Leu- ${ }^{+}$ $B$ cells were recovered after $1 \mathrm{yr}$ in most patients. This pattern of recovery of Leu- $1^{+}$B cell numbers suggests that in this group of patients, de novo chronic GvHD is preceded by "subclinical" acute GvHD and that the development of skin, mucous membrane, and liver injury may be an insensitive way of assessing the presence of acute GvHD.

The function of the Leu-1 antigen on the surface of these cells is unknown. It has been suggested that anti-CD5 antibodies increase the secretion of interleukin 2 (IL-2) (37-39). Preliminary observations suggest that the proliferative responses of partially purified populations of B cells are augmented in the presence of anti-Leu-1; perhaps, due to the division of residual $T$ cells stimulated by endogenous IL-2 or to augmented T cell-dependent, lectin-induced B cell blastogenesis in the presence of IL-2 (unpublished observations). It has been demonstrated that a variety of stimuli including lectins, EBV (40), and Staphylococcus aureus Cowan I (41) can cause IL-2R expression on normal B cells. We were unable to demonstrate IL-2R on either population of $B$ cell by using the monoclonal antibody anti-IL-2R. It is possible that IL-2R are present and functional at a cell-surface density that cannot be detected on the FACS, however, prior studies of IL-2R expression on normal B cells indicated that there is usually adequate surface expression to detect it by our technique $(40,41)$. If Leu-1 expression denotes non-specific activation of B cells, we would expect IL-2R expression in these cells as well. We were unable to detect IL-2R expression on either human fetal Leu- $1^{+}$B cells (unpublished observations) or on Leu- $1^{+}$B cells that appeared after transplantation. Note that although IL-2R expression tends to persist after EBV transformation of IL-2 $R^{+} B$ cells (40), we were unable to detect Leu-1 after transformation of Leu- $1^{+} B$ cells. It is possible that Leu- ${ }^{+}$ B cells were infected with EBV and subsequently stopped expressing Leu-1, or Leu- $1^{+}$B cells are not transformable with EBV; however, Leu-1 clearly was not expressed in a situation where the cells were dividing rapidly. Although in some patients there may have been spontaneous proliferation of Leu- $1^{+}$B cells (unpublished observations), which was not a uniform finding, and in the absence of IL-2R expression, our results suggest that Leu- 1 expression does not reflect non-specific activation of these cells.

The role of Leu- $1^{+}$B cells in the ontogeny of the normal human humoral immune response is also unknown. It is tempting to infer that the recovery of immune cells after bone marrow transplantation in part recapitulates fetal ontogeny. Indeed, although normal adults have very few Leu- $1^{+}$B cells (generally $\sim 1 \%$ of circulating lymphocytes and $<5 \%$ of splenic lymphocytes (14) in adults), they are a major population of B lymphocytes in human fetal spleen and in the peripheral blood of adults and children after bone marrow transplantation. In the human fetus Leu- $1^{+}$B cells comprise $\sim 50 \%$ of splenic B cells and a similar percentage of the total number of B cells in the 1 st 3 mo after transplant, but they are present in detectable numbers for years. Leu- $1^{+}$B cells tend to appear in the peripheral blood before the appearance of Leu- $1^{-}$B cells. Our studies cannot determine whether the expression of Leu-1 is part of the normal development of B cells or if it reflects an antigen that appears as a consequence of specific activation of the cells. As noted above, the evidence suggests that Leu-1 is not a non-specific activation antigen nor does it identify a separate lineage of $\mathbf{B}$ cells in humans.

The recovery of $\mathrm{IgG}$ after transplant was associated with the number of circulating Leu- $1^{+}$B cells. In contrast, serum IgM only correlated with the total number of B cells, and IgA levels 
did not correlate at all. In patients without chronic GvHD, immunoglobulin levels were generally well maintained at or slightly below the normal range. In contrast, patients with chronic GvHD tended to become hypogammaglobulinemic, although individual patients with severe prolonged chronic GvHD may become hypergammaglobulinemic $(7,10)$. The weak correlation between numbers of Leu- $1^{+} B$ cells and maintenance of normal levels of IgG persisted even when analyzed according to the presence or absence of chronic GvHD, however, it was clear from the low value of the correlation coefficients that we did not identify the majority of factors that were responsible for most of the variability of Ig levels. Although both Leu- $1^{+}$and Leu-1 $1^{-}$B cells are present in large numbers in the blood after marrow grafting, the proportion of these cells in lymph nodes and spleen, where most antigens are processed, has not been determined. In the human fetus Leu- $1^{+}$B cells are prominent in the follicles in association with Th cells and follicular dendritic cells $(15,16)$. We have not been able to demonstrate Leu-1-mediated helper activity in normal adults or human fetal spleen in a primary immune response, and the ability of these cells to provide helper activity in a secondary immune response has not been assessed. It is appealing to speculate that the mechanism by which patients are able to maintain IgG levels in the absence of normal Th cell numbers or activity is in part mediated through Leu- $1^{+}$B cells.

\section{Acknowledgments}

We are indebted to Dr. Stephen J. Burakoff for his support and guidance. This work was supported by grants from the National Institutes of Health (AI-23346, CA-18662, RR-00128); American Heart Association, Massachusetts Division, grant 13-506-856; The Milton Fund; and the Dyson Fund. Dr. Antin is a Fellow and Dr. Smith is a Special Fellow of the Leukemia Society of America, Inc.

\section{References}

1. Korsmeyer, S. J., G. J. Elfenbein, C. K. Goldman, S. L. Marshall, G. W. Santos, and T. A. Waldmann. 1982. B cell, helper T cell, and suppressor $\mathrm{T}$ cell abnormalities contribute to disordered immunoglobulin synthesis in patients following bone marrow transplantation. Transplantation (Baltimore). 33:184-190.

2. Witherspoon, R. P., L. G. Lum, R. Storb, and E. D. Thomas. 1982. In vitro regulation of immunoglobulin synthesis after human marrow transplantation. II. Deficient $\mathrm{T}$ and non-T lymphocyte function within 3-4 months of allogeneic, syngeneic, or autologous marrow grafting for hematologic malignancy. Blood. 59:844-850.

3. Witherspoon, R. P., S. Goehle, M. Kretschmer, and R. Storb. 1986. Regulation of immunoglobulin production after human marrow grafting: the role of helper and suppressor $\mathrm{T}$ cells in acute graft-versushost disease. Transplantation (Baltimore). 41:328-335.

4. Pahwa, S. G., R. N. Pahwa, W. Friedrich, R. J. O'Reilly, and R. A. Good. 1982. Abnormal humoral immune responses in peripheral blood lymphocyte cultures of bone marrow transplant recipients. Proc. Natl. Acad. Sci. USA. 79:2663-2667.

5. Lum, L. G., M. C. Seigneuret, R. F. Storb, R. P. Witherspoon, and $\mathrm{E}$. D. Thomas. 1981. In vitro regulation of immunoglobulin synthesis after marrow transplantation. I. T-cell and B cell deficiencies in patients with and without chronic graft-vs-host disease. J. Immunol. 129:431439.

6. Lum, L. G., M. C. Seigneuret, N. Orcutt-Thordarson, J. E. Noges, and $R$. Storb. 1985. The regulation of immunoglobulin synthesis after HLA-identical bone marrow transplantation: VI. Differential rates of maturation of distinct functional groups within lymphoid subpopulations in patients with human marrow grafting. Blood. 65:1422-1433.

7. Witherspoon, R. P., R. Storb, H. D. Ochs, N. Flournoy, K. J.
Kopecky, K. M. Sullivan, H. J. Deeg, R. Sosa, D. R. Noel, K. Atkinson, and E. D. Thomas. 1981. Recovery of antibody production in human allogeneic marrow graft recipients: influence of time posttransplantation, the presence or absence of chronic graft-versus-host disease, and antithymocyte globulin treatment. Blood. 58:360-368.

8. Shiobara, S., R. P. Witherspoon, L. G. Lum, and R. Storb. 1984. Immunoglobulin synthesis after HLA-identical marrow grafting. V. The role of peripheral blood monocytes in the regulation of in vitro immunoglobulin secretion stimulated by pokeweed mitogen. J. Immunol. 132: 2850-2856.

9. Noel, D. R., R. P. Witherspoon, R. Storb, K. Doney, E. M. Mickelson, H. D. Ochs, R. P. Warren, P. L. Weiden, and E. D. Thomas. 1978. Does graft-versus-host disease influence the tempo of immunologic recovery after allogeneic human marrow transplantation? An observation on 56 long-term survivors. Blood. 51:1087-1105.

10. Ringden, O., R. P. Witherspoon, R. Storb, E. Ekelund, and E. D. Thomas. 1980. Increased in vitro B cell IgG secretion during acute graft-versus-host disease and infection. Observations in 50 human marrow transplant recipients. Blood. 55:179-186.

11. Saxon, A., R. E. McIntyre, R. H. Stevens, and R. P. Gale. 1981. Lymphocyte dysfunction in chronic graft-versus-host disease. Blood. 58 : 746-751.

12. Ault, K. A., J. H. Antin, D. Ginsburg, S. H. Orkin, J. M. Rappeport, M. L. Keohan, P. Martin, and B. R. Smith. 1985. The phenotype of recovering lymphoid populations following marrow transplantation. J. Exp. Med. 161:1483-1502.

13. Boumsell, L., H. Coppin, D. Pham, B. Raynal, J. Lemerle, J. Dausett, and A. Bernard. 1980. An antigen shared by a human T cell subset and B cell chronic lymphocytic leukemia cells. J. Exp. Med. 152: 229-234.

14. Antin, J. H., S. G. Emerson, P. Martin, N. Gadol, and K. A. Ault. 1986. Leu- $1^{+}\left(\mathrm{CD5}^{+}\right)$B cells. A major lymphoid subpopulation in human fetal spleen: phenotypic and functional studies. J. Immunol. 136: 505-510.

15. Caligaris-Cappio, F., M. Gobbi, M. Bofill, and G. Janossy. 1982. Infrequent normal B lymhocytes express features of B-chronic lymphocytic leukemia. J. Exp. Med. 155:623-628.

16. Bofill, M., G. Janossy, M. Janossa, G. D. Burford, G. J. Seymour, P. Wernet, and E. Kelemen. 1985. Human B cell development. II. Subpopulations in the human fetus. J. Immunol. 134:1531-1538.

17. Gadol, N., and K. A. Ault. 1986. Phenotypic and functional characterization of human LEU1 (CD5) B cells. Immunol. Rev. 23-34.

18. Gobbi, M., F. Caligaris-Capio, and G. Janossy. 1983. Normal equivalent cells of $B$ cell malignancies: analysis with monoclonal antibodies. Br. J. Haematol. 54:393-403.

19. Miller, R. A., and J. Gralow. 1984. The induction of Leu-1 antigen expression in human malignant and normal $B$ cells by phorbol myristic acetate (PMA). J. Immunol. 133:3408-3414.

20. Hayakawa, K., R. R. Hardy, D. R. Parks, and L. A. Herzenberg. 1983. The "Ly-1 B" cell population in normal, immunodefective, and autoimmune mice. J. Exp. Med. 157:202-218.

21. Hayakawa, K., R. R. Hardy, M. Honda, L. A. Herzenberg, A. D. Steinberg, and L. A. Herzenberg. 1984. Ly-1 B cells: functionally distinct lymhocytes that secrete IgM autoantibodies. Proc. Natl. Acad. Sci. USA. 81:2494-2498.

22. Sidman, C. L., L. D. Shultz, R. R. Hardy, K. Hayakawa, and L. A. Herzenberg. 1986. Production of immunoglobulin isotypes by Ly$1^{+}$B cells in viable motheaten and normal mice. Science (Wash. DC). 232:1423.

23. Okumura, K., K. Hayakawa, and T. Tada. 1982. Cell-to-cell interaction controlled by immunoglobulin (Ig) genes: role of Thy-1Lyt-1 ${ }^{+}, \mathrm{Ig}^{+}\left(\mathrm{B}^{\prime}\right)$ cell in allotype-restricted antibody formation. J. Exp. Med. 156:443-453.

24. Sherr, D. H., and M. E. Dorf. 1984. An idiotype-specific helper population that bears immunoglobulin, Ia, and Lyt-1 determinants. $J$. Exp. Med. 159:1189-1200.

25. Sidman, C. L., J. D. Marshall, N. C. Masiello, J. B. Roths, and L. D. Shultz. 1984. Novel B-cell maturation factor from spontaneously 
autoimmune, viable motheaten mice. Proc. Natl. Acad. Sci. USA. 81: 7199-7202.

26. Hayakawa, K., R. R. Hardy, L. A. Herzenberg, and L. A. Herzenberg. 1985. Progenitors for $L y-1$ B cells are distinct from progenitors for other B cells. J. Exp. Med. 161:1554-1568.

27. Smith, B. R., E. C. Guinan, R. Parkman, J. Ferrara, R. H. Levey, D. G. Nathan, and J. M. Rappeport. 1981. Efficacy of a cyclophosphamide-procarbazine-antithymocyte serum regimen for prevention of graft rejection following bone marrow transplantation for transfused patients with aplastic anemia. Transplantation (Baltimore). 39:671-673.

28. Parkman, R., J. M. Rappeport, S. Hellman, J. M. Lipton, B. Smith, R. Geha, and D. G. Nathan. 1984. Busulfan and total body irradiation as antihematopoietic stem cell agents in the preparation of patients with congenital bone marrow disorders for allogeneic bone marrow transplantation. Blood. 64:852-857.

29. Reinherz, E. L., R. Geha, J. M. Rappeport, M. Wilson, A. C. Penta, R. E. Hussey, K. A. Fitzgerald, J. F. Daley, H. Levine, F. S. Rosen, and S. F. Schlossman. 1982. Reconstitution after transplantation with T-lymphocyte-depleted HLA haplotype-mismatched bone marrow for severe combined immunodeficiency. Proc. Natl. Acad. Sci. USA. 79: 6047-6051.

30. Ginsburg, D., J. H. Antin, B. R. Smith, S. H. Orkin, and J. M. Rappeport. 1985. Origin of cell populations after bone marrow transplantation. Analysis using DNA sequence polymorphisms. J. Clin. Invest. 75:596-603.

31. Smith, B. R., R. Parkman, J. Lipton, D. G. Nathan, and J. M. Rappeport. 1985. Efficacy of a short course (four doses) of methotrexate following bone marrow transplantation for prevention of graft-versushost disease. Transplantation (Baltimore). 39:326-329.

32. Thomas, E. D., R. Storb, R. A. Clift, A. Fefer, F. L. Johnson, P. E. Neiman, K. G. Lerner, H. Glucksberg, and C. D. Buckner. 1975. Bone marrow transplantation. N. Engl. J. Med. 292:832-843, 895-902.

33. Shulman, H. M., K. M. Sullivan, P. L. Weiden, G. B. MacDonald,
G. E. Striker, G. E. Sale, R. Hackman, M. S. Tsoi, R. Storb, and E. D. Thomas. 1984. Graft-versus-host syndrome in man. A long-term clinicopathologic study of 20 Seattle patients. Am. J. Med. 69:204-217.

34. Peto, R., M. C. Pike, P. Armitage, N. E. Breslow, D. R. Cox, S. V. Howard, N. Mantel, K. McPherson, J. Peto, and P. G. Smith. 1977. Design and analysis of randomized clinical trials requiring prolonged observation of each patient. II. Analysis and examples. Br. J. Cancer. 35:1-39.

35. Mauch, P., J. M. Lipton, B. Hamilton, J. Obbagy, M. Kudisch, D. Nathan, and S. Hellman. 1984. Lethal graft-versus-host disease: Modification with allogeneic cultured donor cells. Blood. 63:1112-1119.

36. Smith, B. R., J. M. Rappeport, S. J. Burakoff, and K. A. Ault. 1986. Clinical correlates of unusual circulating lymphocytes appearing post marrow transplantation. UCLA (Univ. Calif. Los Ang.) Symp. Mol. Cell. Biol. New Ser. 53:659-663.

37. Santon, T., T. L. Stevens, J. A. Ledbetter, and D. Wofsky. 1986. Anti-Ly-1 antibody induces interleukin-2 release from T cells. J. Immunol. 136:1734-1737.

38. Ledbetter, J. A., P. J. Martin, C. E. Spooner, D. Wofsky, T. T. Tsu, P. G. Beatty, and P. Gladstone. 1985. Antibodies to Tp67 and Tp44 augment and sustain proliferative responses of activated T cells. J. Immunol. 135:2331-2336.

39. Thomas, Y., E. Glickman, J. DeMartino, J. Wang, G. Goldstein, and $\mathrm{L}$. Chess. Biologic functions of the OKT1 T cells surface antigen. I. The T1 molecule is involved in helper function. 1984. J. Immunol. 133: 724-728.

40. Waldmann, T. A., C. K. Goldman, R. J. Robb, J. M. Depper, W. J. Leonard, S. O. Sharrow, K. F. Bongiovanni, S. J. Korsmeyer, and W. C. Greene. 1984. Expression of Interleukin-2 receptors on activated human B cells. J. Exp. Med. 160:1450-1466.

41. Tsudo, M., T. Uchiyama, and H. Uchino. 1984. Expression of TAC antigen on activated normal human B cells. J. Exp. Med. 160: 612-617. 